was 26.90 per cent. ; by the acid method it was 31.45 per cent., a difference in this case of 4.55 per cent., proving conclusively that, while the acid method may be very useful when used by an experienced chemist at a cement works making regularly a uniform product, it is not at all to be relied on as a universal method to be used indiscriminately for the determination of silica in all cements.

[CONTRIBUTIONS FROM THE UNITED STATES LABORATORY, BOSTON, MASS.]

\title{
ANALYTICAL RESEARCH ON SOD OIL.
}

By Erastus Hopkixs, D. I. Coburn, aNd EDW. Spiller.

Received November 3,1898 .

$\mathrm{C}$ XCEPTING among the tanners very little is known of this L oil, and among them it is known only in its principal application. Its chemical properties are little known and the aim of this paper is to state the main chemical facts regarding this oil, thousands of tons of which are used each year in the currying of leather.

To better understand what sod oil is, let us say that it is an oil which has for its basis various non-drying oils and greases, but almost exclusively cheap fish oils. These oils are put into the leather for currying purposes and the excess is extracted by various methods. The extracted oil has undergone a change from the original oil by coming in contact with the leather and becomes what is known in commerce as 'sod oil,' more highly valued by the tanners than the original oil.

In "Oils, Fats and Waxes," Benedikt and Lewkowitsch describe this oil as follows: "Sod oil or dégras is the waste fat obtained in the chamoising process and is used for currying purposes; i. e., dressing bark-tanned leather." "Dégras proper might be said to be the oil obtained from skins in the manufacture of chamois leather, while its allied substance, sod oil, is the oil obtained from ordinary leather.

The principal oils used from which to make sod oil are menhaden and cod oils, but various oils (even olive oil) and greases may be used, and hence give to the sod oil a variation in constants which have so extended a range that they might not be constants at all. 
Sod oil has the odor of leather and is generally of such a character that it forms a separating emulsion. The color may be a light yellow to a dark brown. Its viscosity may vary from that of a pure oil to a thin grease with a specific gravity of from 0.96 to 0.99 .

The noticeable chemical characteristics are the presence of a so-called 'dégras former' hide fragments, and a high ash content due to the leather from which the oil is extracted. Another point of interest is the great variation in moisture and mineral acid of the oil, as well, of course, as of all its constants.

It is claimed that the higher the percentage of 'dégras former' and the lower the percentage of mineral acid, the more valuable the oil, but commercially the price of the oil does not seem to be governed by these facts, but is bought and sold on firm names, which is undoubtedly due to the fact that tanners still work by the "thumb rule" rather than by being advised by scientific research.

We hope in this paper to bring out the general analytical facts regarding the oil itself and later to work up the almost unknown dégras former which is described as a resinous substance (not a resin) found in sod oil, melting at $65^{\circ}-67^{\circ}$, and showing certain degrees of solubility with various solvents. Dégras former, as it occurs in sod oil, can be extracted from sod oil by petroleum ether, but in its pure state dégras former is insoluble in this menstruum.

Sod oil contains unsaponifiable and saponifiable oil, the unsaponifiable being undoubtedly due to the unsaponifiable matter in the fish oil used. It contains also moisture, soap and hide fragments, ash and dégras former, and we have endeavored to find a rapid process by which moisture, oil, soap, and hide fragments could be determined which will be described below under that subject. The samples of sod oil taken were commercial and imported sod oils.

MOISTURE, OIL, SOAP, AND HIDE FRAGMENTS.

After some preliminary work on the determination of moisture, oil, soap, and hide fragments, it was found that the methods described by Benedikt and Lewkowitsch were rather tedious, and the results in our hands were unsatisfactory. This was 
particularly true of the moisture which we attempted to determine by weighing the oil with pure ignited sand (enough to absorb it), and by drying at $120^{\circ} \mathrm{C}$. in a drying oven. We were unable to get a constant weight by this method, the oil continuing to lose weight even after five or six days drying.

The following method was then devised and found to give accurate results :

For the analyses we used a test-tube of sixty to eighty $\mathrm{mm}$. in length and fifteen to twenty $\mathrm{mm}$. in diameter with a small hole blown in its bottom, and furnished with a platinum wire for suspending the tube while weighing. A small wad of absorbent cotton is first inserted into the tube $(a)$, then an ashless filter paper of twelve $\mathrm{cm}$. diameter is folded about the finger (placing the tip of the finger in the center of the paper) and placed in the test-tube so that upon withdrawing the finger from the inside of the filter-paper, the paper with its closed end on the cotton wad takes the shape of the test-tube and forms a filter-paper capsule which prevents the solid matter of the oil from being mechanically carried through the cotton. The capsule is made of filter-paper because it was found that the ordinary capsule is

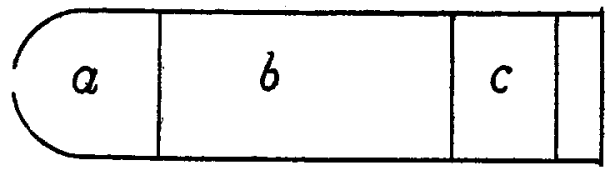

too large and heavy for this work. The inside of this filterpaper capsule is filled with closely rolled ashless filter-papers $(b)$ and a cotton wad is put on top $(c)$. This is dried and weighed for tare. The upper wad is then removed and the sod oil introduced and absorbed by the filter-paper, care being taken that the oil does not saturate the lower cotton wad. The upper wad is then replaced and the weight taken gives the charge of oil. The test-tube after weighing is placed in a water-jacket dryingoven and attached by the lower end of the tube to a suction-pipe which, under slight pressure, draws hot air through the test-tube from the top, out through the hole in the bottom. By using a water-jacket oven the temperature is ensured to remain constant at $100^{\circ} \mathrm{C}$. and the suction of hot air makes the drying to constant weight rapid when compared to other methods used for the 
294 ERASTUS HOPKINS, D. L, COBURN, AND EDW. SPILIER.

drying of oils. The loss in weight gives the moisture. The tube containing the anhydrous oil is placed in a Soxhlet apparatus, and the oil is extracted by $40^{\circ}$ petroleum-ether. A weight taken on the dried tube, or better on the extracted oil, gives the oil, etc., soluble in petroleum-ether. There are now left in the tube soap, hide fragments, and ash. The test-tube is next treated in the Soxhlet with alcohol which extracts the soap. A weight on the tube gives (I) by loss, soap, etc., soluble in alcohol, (2) hide fragments and ash insoluble in petroleum-ether and alcohol, and upon igniting the cotton and filter-paper this ash is determined and the difference gives the amount of hide fragments.

The ash found is lower than total ash, and this difference is accounted for by finding fractions of the ash in the oil and soap. For absolutely accurate analytical work the ash soluble in petroleum-ether and alcohol should be determined and subtracted from the oil and soap and added to the ash of ignition, but the error is so small that for commercial work this can be omitted as we have omitted it in this research. Upon making determinations of these ash fractions we have found that their sum checks the total ash. All of these determinations are made upon one charge which is an advantage in itself.

The process is rapid and gives very accurate results, and its use is not in any way confined to sod oil, but may be used in the analysis of all oils and greases where drying and extraction are required. Because of the necessarily small test-tube used we found that a Soxhlet apparatus with a two-inch siphon tube instead of the regulation four-inch tube was better adapted to the work.

TOTAL ASH.

This is determined by igniting the oil in a tared platinum dish. The ash is found to be high, and consists chiefly of calcium, iron, and the alkalies for bases with carbon dioxide and sulphur trioxide for the acid radical. The calcium comes from the lime used in liming hides.

\section{DÉGRAS FORMER.}

For this determination Jean's method, mentioned by Benedikt and Lewkowitsch, was followed except in certain modifica- 
tions, which we found to be necessary because of the lack of concordant results. His method advises decantation of the liquid from the crust of dégras former: this we found inaccurate because by decantation small particles of dégras former were carried away, and for this reason we used a filter and transferred the crust of dégras former upon the filter. Another point which he omits to state is that oil often adheres to the dégras former and thus causes too high results; this we obviated by washing the dégras former with petroleum-ether after having washed it free of acid and salt. Jean dissolves the dégras former in ether but we found that it took too long and too much solvent, whereas it is readily soluble in absolute alcohol and gives a pure product melting at the required temperature.

Our modified Jean's method is as follows: The oil is saponified according to the method for the determination of unsaponifiable matter. (The unsaponifiable number may thus be determined on the same charge.) The saponifiable matter of the sod oil which contains the easily saponifiable dégras former, is heated to drive off the alcohol and ether used in the saponification. The saponifiable matter is taken up with water, and the soap is precipitated hot with an excess of salt. The mixture is cooled and filtered off into a beaker and hydrochloric acid is added to the filtrate. The dégras former is precipitated by hydrochloric acid in flocks which unite on boiling and adhere to the sides of the beaker on cooling, leaving a soft brown crust on the top of the solution. The liquid is filtered off (filtering being used rather than decantation to prevent loss); the dégras former is washed with water free from acid and salt and then with petroleum-ether free from oil. It is then dissolved on the filter with absolute alcohol; the alcohol is driven off and the dégras former weighed. This dégras former should melt at $65^{\circ}-67^{\circ} \mathrm{C}$.

GENERAL ANALYTICAL TESTS.

The analytical tests, common to oil analysis, and made by us with only a few modifications, were the determinations of total $\mathrm{KOH}$, mineral acid, total acid, from which were calculated the $\mathrm{KOH}$ number, ether number, and free fatty acid number, also of Reichert-Meissl, iodine value, unsaponifiable, and iodine of unsaponifiable. All of these were calculated to anhydrous sod 
oil and also to numbers "In terms of oil, etc., soluble in petroleum-ether." The methods are so generally well known that they are not given excepting where modifications of the same were found advisable.

The total $\mathrm{KOH}$ was determined upon two and one-half grams of the oil and the final titration was made with half-normal hydrochloric acid with phenolphthalein as indicator. It is rather difficult to determine the end-point in these oils because of the high color of the oil, but if, when the end-point is near, the flask is vigorously shaken a foam will appear on the surface of the liquid. If a drop of phenolphthalein is now added, the foam will become pink until the neutral point is reached. The calculation is to milligrams of potassium hydroxide per one gram of sod oil.

The mineral acid was determined by boiling in distilled water two to two and one-half grams of the sod oil and washing on a filter with hot distilled water until all the mineral acid was removed. This is titrated with standard sodium hydroxide and calculated to milligrams of potassium hydroxide per one gram of sod oil.

The total acid was determined by dissolving two grams of oil in hot methyl alcohol in which all the free acid has been neutralized. This alcoholic solution is titrated with standard sodium hydroxide and calculated to milligrams of potassium hydroxide per one gram of sod oil.

The $\mathrm{KOH}$ number is calculated as the difference between the total $\mathrm{KOH}$ and mineral acid.

The ether number is calculated as the difference between total $\mathrm{KOH}$ and total acid.

The free fatty acid is calculated as the difference between the total acid and mineral acid.

The Reichert-Meissl value, iodine number and unsaponifiable number were determined by the common methods with no modifications.

The petroleum-ether used throughout these experiments and analyses was $40^{\circ}$ naphtha which as a separating medium was found to be essential, and as a solvent acted more rapidly and with better results than the lower fractions of naphtha.

The numbers obtained by the above methods differ very 

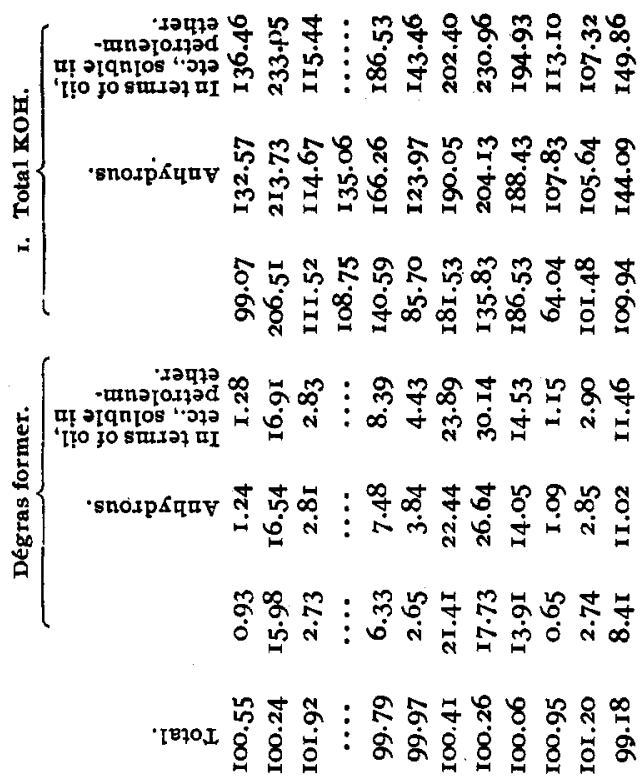

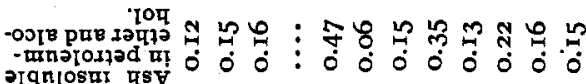

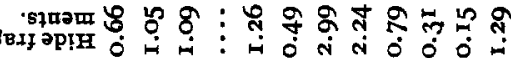

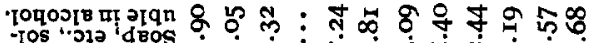

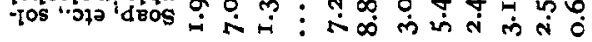

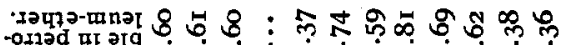

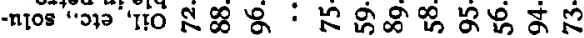

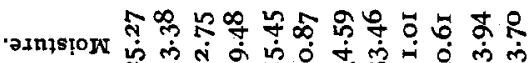

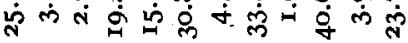

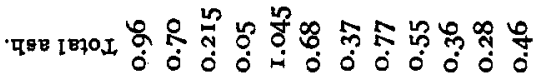

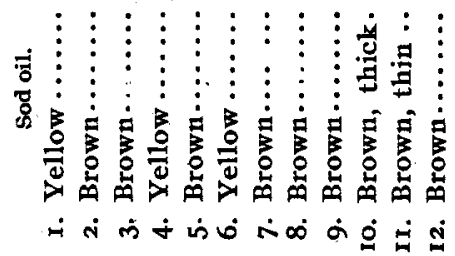


298 ERASTUS HOPKINS, D. L. COBURN, AND EDW. SPILIER.
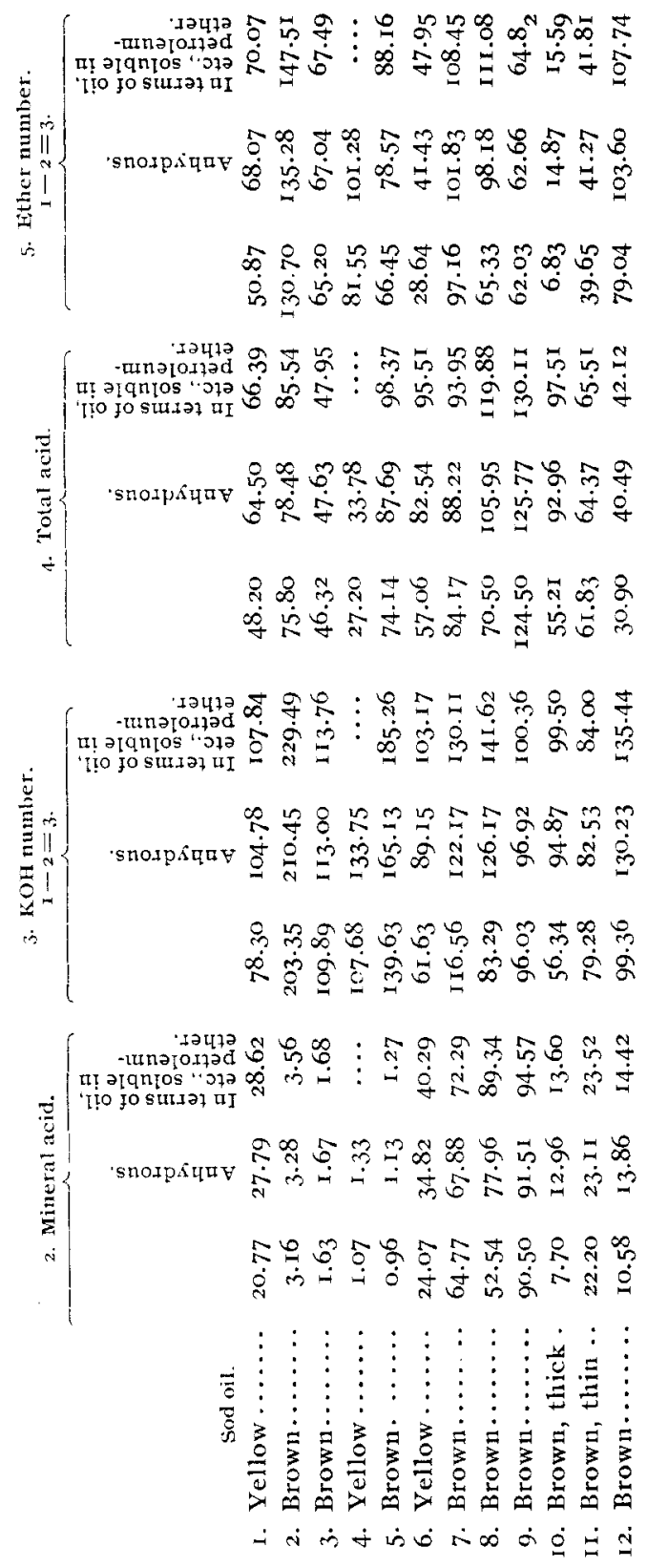
. วrqug!nodes

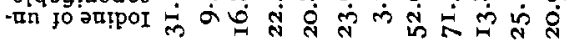
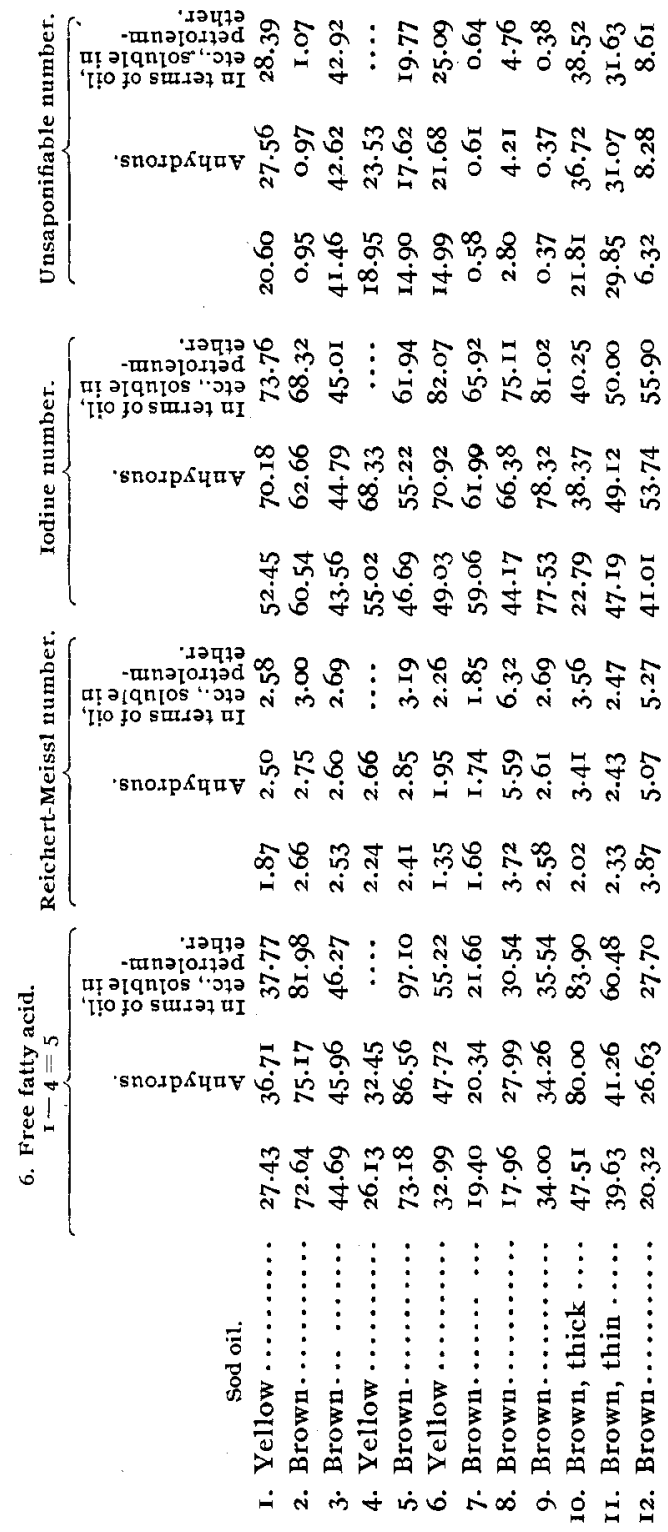
widely, as can be seen by the accompanying tables, and this is true whether the numbers are referred to the anhydrous sod oil or to the "oil, etc., soluble in petroleum ether." Calculations were also made in terms of "oil, etc., soluble in petroleum-ether less dégras former," but as no concordant results were obtained we did not think it necessary to add another column of figures.

The reason for this variation in figures seems to be the great variety of oils which are used for the making of sod oil as well as the different modifications of treating the same initial oil by different makers. Still, sod oil, by a complete analysis as described above, can be easily distinguished from other oils.

\section{CORRESPONDENCE RELATING TO THE BERZELIUS MEMORIAL SERVICES.}

Held in Stockholm, Sweden, October 7,1898 , on the occasion of the fiftieth anniversary of the death of Berzelius.

\section{"The American Chemical Society:}

Messieurs, chers et honorés collègues: À l'occasion du cinquantieme anniversaire de la mort de Berzelius, l'Académie des Sciences de Stockholm, la Faculté de Médicine de Stockholm (Karolinska Institutet), l'Académie d'Agriculture et la Société des Médecins de Suède se proposent de célébrer la memoire du grand savant par une fête commémorative.

Au nom de ces institutions nous avons l'honneur de vous prier de bien vouloir déléguer un de vos membres pour prendre part à cette solennité, qui aura lieu à Stockholm le 7 octobre 1898 .

Veuillez, messieurs et chers collègues, agréer l'assurance de nos sentiments les plus distingués.

$$
\begin{aligned}
& \text { A. E. NORDENSKIOLD, } \\
& \text { L. F. NILSON, } \\
& \text { F. LENNMALM, } \\
& \text { Christian ZOVEN, } \\
& \text { Severin Jolin. } \\
& \text { "55 I Putnam Ave, Brooklyn, N. Y., } \\
& \text { September 30, I } 898 \text {. }
\end{aligned}
$$

Dr. A. E. Nordenskiold, Academy of Sciences, Stockholm, Sweden.

Dear Sir: I have the honor to acknowledge the receipt of the communication sent by yourself and colleagues announcing the solemuities in commemoration of Berzelius, on the occasion of the fiftieth anniversary of his death, to be held in Stockholm, 